\title{
Identification of Differently Regulated Proteins after Fusarium graminearum Infection of Emmer (Triticum dicoccum) at Several Grain Ripening Stages
}

\author{
Christina Trümper ${ }^{1 *}$, Katrin Paffenholz ${ }^{2}$, Inga Smit ${ }^{1}$, Philip Kössler ${ }^{3}$, Petr Karlovsky ${ }^{3}$, \\ Hans Peter Braun ${ }^{2}$ and Elke Pawelzik ${ }^{1}$ \\ ${ }^{1}$ Quality of Plant Products, Department of Crop Sciences, Faculty of Agriculture, \\ Georg-August-University of Göttingen, DE-37075 Göttingen, Germany \\ ${ }^{2}$ Institute of Plant Genetics, Faculty of Natural Sciences, Leibniz University of Hannover, \\ DE-30419 Hannover, Germany \\ ${ }^{3}$ Molecular Phytopathology and Mycotoxin Research Division, Department of Crop Sciences, Faculty of \\ Agriculture, Georg-August University of Göttingen, DE-37077 Göttingen, Germany
}

Received: July 29, 2014

Accepted: March 23, 2015

\begin{abstract}
Summary
This study was conducted to improve the knowledge of molecular processes involved in the interaction between Fusarium graminearum and emmer in the course of grain ripening. Emmer plants were artificially inoculated with a F. graminearum spore suspension at anthesis. In the course of grain ripening from milk ripe to plant death stage, grains at four phenological growth stages were collected for analysis. The infection degree was evaluated based on the F. graminearum DNA content in emmer grain infolding tissues (glumes and rachis). For proteome analysis the albumin and globulin fractions of emmer grains, consisting of proteins with various functions related to the development and stress response, were analysed regarding the changes due to Fusarium infection by two-dimensional gel electrophoresis. Altogether, forty-three proteins affected by infection were identified by mass spectrometry. Enzymes detoxifying reactive oxygen species were regulated at all developmental stages. In the early stage of grain development, the abundance of proteins related to stress response, such as 2-Cys peroxiredoxin, a chitinase, a xylanase inhibitor and a spermidine synthase was increased. During later stage of grain development, the abundance of stress-related proteins, such as chitinases, heat shock proteins and an $\alpha$-amylase inhibitor-like protein, decreased. During all ripening stages, but especially during medium milk stage (BBCH 75) and soft dough stage (BBCH 85), the abundance of proteins related to carbon metabolism, starch and protein biosynthesis as well as photosynthesis increased due to F. graminearum infection. At the plant death stage (BBCH 97) the abundance of only two proteins related to metabolism decreased.
\end{abstract}

Key words: Fusarium head blight, grain development, emmer, plant proteomics, defence proteins

\section{Introduction}

Fusarium head blight (FHB) is a cereal disease causing significant yield losses and in particular accumulation of several mycotoxins, such as trichothecenes deoxyniva- lenol (DON), nivalenol (NIV), their acetylated derivatives and zearalenone (ZEA) (1). The predominant species infesting cereals in Europe are Fusarium graminearum Schwabe (Gibberella zeae Schwein. Petch.) and Fusarium 
culmorum (W.G. Smith). The most critical period for infection and colonisation of cereal ears with Fusarium spp. is during the anthesis and the first half of the grain filling stage (2). Multiple mechanisms of defence and resistance are known to exist in plants. Two main types of resistance to FHB are widely recognized: type I resistance to initial infection and type II resistance to fungal spread within adjacent tissues. Furthermore, resistance against Fusarium infection involves the ability to degrade trichothecenes and the inhibition of trichothecene biosynthesis of the pathogen (3). An effective method to control FHB is the cultivation of resistant cultivars (4). Therefore, more information about infection mechanisms of the pathogen and respective defence strategies of the plants is needed.

Emmer is an ancient tetraploid crop with hulled grain. The domestication of emmer was the first step towards the evolution of free-threshing tetraploid durum wheat and hexaploid bread wheat. Emmer cultivars are supposed to be resistant to fungal diseases such as stem rust, prevalent in wet areas. Some cultivars are tolerant of heat and drought stress. Thus, emmer represents a useful genetic resource for resistance breeding in wheat concerning biotic and abiotic stresses (5).

So far, a few studies have been available concerning the sources of FHB resistance in emmer $(6,7)$. Oliver et al. (7) found a wide variation in the susceptibility of emmer to $F$. graminearum, with varieties ranging from highly resistant to highly susceptible. A study of Buerstmayr et al. (6) on wild emmer cultivars from Israel showed that most of the plants were highly susceptible to $F$. graminearum. Nevertheless, occasionally genotypes showing lower infection rates have been found, which may serve as a source for resistance breeding in emmer and wheat.

Several proteomic studies have been performed, analysing various proteins with a potential role in plant-fungus interaction. These studies provide an insight into pathogenicity and host resistance against Fusarium spp. infection of cereals. Most of them focussed on the initial infection of wheat spikes $(8-10)$ and barley spikes $(11,12)$ during the first days after inoculation at anthesis. According to these studies up to three days after inoculation the abundance of many proteins related to carbon metabolism, photosynthesis, oxidative stress and fungal cell wall degradation was affected by $F$. graminearum infection of the spikes. Regarding the proteins involved in carbon metabolism and photosynthesis, controversial results concerning changes of abundances were described. Wang et $a l$. (8) found that abundances of most of these proteins decreased after infection of wheat spikes, whereas Zhou et al. (9), Shin et al. (10) and Yang et al. (11) ascertained an increased energy metabolism in infected barley and wheat heads. Furthermore, pathogenesis-related proteins, such as chitinases and thaumatin-like proteins, as well as proteins involved in oxidative stress response were predominantly accumulated during the early infection of wheat and barley (9-11).

To our knowledge, little research has been carried out considering the differential expression of proteins in response to Fusarium infection at later stages of infection in the course of grain ripening. Dornez et al. (13) analysed wheat kernels 5, 15 and 25 days post anthesis (water ripe, milk ripe and soft dough stage) and inoculation with $F$. graminearum focussing on xylanase inhibitor proteins (XIP). Additionally, the abundance of several pathogenesis-related (PR) proteins, such as peroxidases and chitinases predominantly increased and of thaumatin-like proteins as well as a wheatwin-2 precursor decreased (13). Earlier studies investigated the proteome of mature emmer and naked barley grains long after Fusarium infection $(14,15)$. These studies also revealed an increase in stress-related proteins, such as serine protease inhibitor and thaumatin-like protein, and decrease in proteins related to oxidative stress as well as chitinase in emmer. In naked barley increased abundance of transcriptional regulatory proteins and protease inhibitors was detected. Furthermore, the abundance of proteins involved in starch synthesis decreased in both varieties $(14,15)$.

In the current study, changes of specific proteins due to $F$. graminearum infection were investigated in four grain development stages from milk ripe to plant death of emmer. The aim of this work is to investigate $F$. graminearum infection-induced changes in protein expression in emmer grain and to elucidate how these changes depend on the ripening stage and the progress of infection. Albumins and globulins possess multiple functions in growth, development and stress response of cereals (16). The investigation therefore focused on albumin and globulin protein fractions.

\section{Materials and Methods}

\section{Experimental design}

The field trial was carried out at Marienstein (Nörten-Hardenberg), near Göttingen, Germany, in 2011 as block design with eight plots of three to six meters with the emmer genotype Linie 9-102 (IPK Gatersleben, Leibniz Institute of Plant Genetics and Crop Plant Research, Stadt Seeland, Germany). The seeding rate was adjusted for a density of 280 germinable grains per $\mathrm{m}^{2}$. Four plots were artificially spray-inoculated with Fusarium graminearum spore suspension $\left(10^{5}\right.$ spores per $\mathrm{mL} ; 50 \mathrm{~mL}$ per $\left.\mathrm{m}^{2}\right)$ during flowering using a knapsack sprayer. The minimum space between artificially inoculated plots and non-inoculated plots (referred to as control) was five meters. Three predominant DON-producing strains of $F$. graminearum (FG 142, FG 143 and FG 144) were used for conidiospore production according to previous studies $(14,15)$. The strains were isolated from wheat spikes in Bavaria and are reference material from the Division of Plant Pathology and Crop Protection at the Department of Crop Science of the Georg-August-University of Göttingen, Germany. The strains were cultured as a mixture of equal proportions on an autoclaved wheat straw suspension, consisting of $9 \mathrm{~g}$ of straw (ground to $1.5 \mathrm{~mm}$ size), $500 \mathrm{~mL}$ of distilled water and $50 \mathrm{mg}$ of streptomycin sulphate, for ten days at $20^{\circ} \mathrm{C}$. The spore density was quantified with a Fuchs-Rosenthal chamber $\left(0.0625 \mathrm{~mm}^{2}\right.$, depth $0.2 \mathrm{~mm}$; Hausser Scientific, PA, Horsham, USA). Fifty ears from each plot were randomly sampled by use of scissors at the development stages BBCH 75, 85, 87 and 97 as documented in Table 1. The samples were freeze dried and stored at $-80{ }^{\circ} \mathrm{C}$ until sample preparation. The development stages were identified according to the $\mathrm{BBCH}$-scale (17). The $\mathrm{BBCH}$-scale defines the phenological growth stages with 
Table 1. Phenological growth stages of emmer plants and the corresponding days after inoculation (anthesis: 0 days after inoculation)

\begin{tabular}{lc}
\hline Phenological growth stages (BBCH code) & Days after inoculation \\
\hline Medium milk (75) & 19 \\
Soft dough (85) & 25 \\
Hard dough (87) & 32 \\
Plant death and collapsing (97) & 39
\end{tabular}

$\mathrm{BBCH}=$ Biologische Bundesanstalt, Bundessortenamt und Chemische Industrie (Federal Institute of Biology, Federal Plant Variety Office and Chemical Industry), Germany

a standardised decimal code. The abbreviation $\mathrm{BBCH}$ derives from Biologische Bundesanstalt, Bundessortenamt und Chemische Industrie (Federal Institute of Biology, Federal Plant Variety Office and Chemical Industry), Germany.

\section{Sample preparation and protein extraction}

For proteomics analysis, grains were manually removed from the ears and milled with a ball mill (Retsch ${ }^{\circledR}$; Mixer Mill MM 400, Haan, Germany). Grain samples were stored at $-80{ }^{\circ} \mathrm{C}$ prior to analysis. Albumins and globulins were extracted with $50 \mathrm{mM}$ sodium phosphate buffer $(\mathrm{pH}=7.8)$, containing $0.1 \mathrm{M} \mathrm{NaCl}$ and $0.2 \%$ protease inhibitor cocktail (Sigma-Aldrich, Taufkirchen, Germany). A mass of $100 \mathrm{mg}$ of flour was extracted with $1 \mathrm{~mL}$ of sodium phosphate buffer and stirred for $2 \mathrm{~h}$ at $4{ }^{\circ} \mathrm{C}$. After centrifugation at $8000 \times g$ and $4{ }^{\circ} \mathrm{C}$ for $10 \mathrm{~min}, 500 \mu \mathrm{L}$ of the supernatant were transferred into another tube. A volume of $1.5 \mathrm{~mL}$ of ice-cold trichloroacetic acid (TCA) in acetone was added to the supernatants and the mixture was stored at $-20{ }^{\circ} \mathrm{C}$ overnight to precipitate the protein. The cold samples were centrifuged $\left(8000 \times g\right.$ at $4{ }^{\circ} \mathrm{C}$ for 10 min) and the supernatants were discarded. The pellets were rinsed three times with cold acetone under stirring for $10 \mathrm{~min}$ at $4{ }^{\circ} \mathrm{C}$ and then centrifuged as before. The pellets were dried at $100 \mathrm{mbar}$ for $10 \mathrm{~min}$ in a vacuum concentrator (RVC 2-25 CD, Christ $\mathrm{GmbH}$, Osterode am Harz, Germany) and resuspended in $500 \mu \mathrm{L}$ of lysis buffer (6 M urea, $2 \mathrm{M}$ thiourea and $0.2 \%$ Pharmalyte buffer; BioRad, Munich, Germany), pH=3-10, 2 \% CHAPS (Carl Roth, Karlsruhe, Germany), 2 \% dithiothreitol, $0.2 \%$ protease inhibitor cocktail (Sigma-Aldrich) and $0.002 \%$ Bromophenol Blue. For solubilisation of the protein, samples were shaken for $1 \mathrm{~h}$ at $33{ }^{\circ} \mathrm{C}$ in a Thermomixer (Eppendorf, Hamburg, Germany). Finally, protein concentrations were determined with a 2-D Quant Kit (GE Healthcare Life Sciences, Freiburg, Germany) and adjusted to a concentration of $1 \mu \mathrm{g}$ per $\mu \mathrm{L}$.

\section{Fusarium graminearum DNA}

Total DNA was extracted from $100 \mathrm{mg}$ of grain hull tissue after removing the kernels according to a CTAB protocol described by Brandfass and Karlovsky (18). The content of $F$. graminearum DNA was determined by species-specific real-time PCR with a standard prepared from a pure F. graminearum culture and quantified by densitometry (19).

\section{Quantitative LC-MS/MS of DON}

Grain samples were analysed by high-performance liquid chromatography tandem mass spectrometry (LC-MS/ MS), as described by Adejumo et al. (20) in the laboratory of Molecular Phytopathology and Mycotoxin Research, Department of Crop Sciences, Georg-August-University of Göttingen, Germany.

\section{Two-dimensional gel electrophoresis}

For isoelectric focusing (IEF), commercially available immobilized $\mathrm{pH}$ gradient (IPG) strips $(\mathrm{pH}=3-10,17 \mathrm{~cm}$, BioRad) were used. A volume of $300 \mu \mathrm{L}$ of the protein sample was loaded into a tray. The IPG strips were rehydrated overnight, covered with $1 \mathrm{~mL}$ of mineral oil to prevent evaporation. The IEF was performed in the Protean ${ }^{\circledR}$ IEF cell (BioRad) under the following conditions: $15 \mathrm{~min}$ at $0-250 \mathrm{~V}, 3 \mathrm{~h}$ at $250-10000 \mathrm{~V}$ and $10000-60000 \mathrm{~V}$ for hours. The rapid ramp was chosen, the current was set to $50 \mu \mathrm{A}$ per gel and the temperature was $20^{\circ} \mathrm{C}$. Afterwards, the IPG strips were incubated in two buffer agents for 15 min: the first solution contained $6 \mathrm{M}$ urea, $2 \%$ SDS, 0.375 M Tris-HCL ( $\mathrm{pH}=8.8$ ), $20 \%$ glycerol and $2 \%$ DTT, and the second solution contained $6 \mathrm{M}$ urea, $2 \%$ SDS, $0.375 \mathrm{M}$ Tris-HCL (pH=8.8), $20 \%$ glycerol and $2.5 \%$ iodoacetamide. Finally, the strips were rinsed with SDS-PAGE running buffer (25 mM Tris, $192 \mathrm{mM}$ glycine and $0.1 \%$ SDS). SDS-PAGE was performed in the Protean ${ }^{\circledR}$ II xi Cell (BioRad) in $12 \%$ polyacrylamide gels $(20 \mathrm{~cm} \times 20 \mathrm{~cm} \times 1 \mathrm{~mm})$ with a current of $30 \mathrm{~mA}$ per gel. The staining was performed with a modified colloidal Coomassie G-250 staining (blue silver) (21).

\section{Data analysis}

The gels were scanned with an image scanner (Epson Expression $^{\mathrm{TM}} 10000$ XL; Epson, Long Beach, CA, USA) using the LabScan v. 6.0 software (GE Healthcare Bio-Sciences $A B$, Uppsala, Sweden). The gel images were saved as TIF files and analysed using the PDQuest Basic v. 8.0.1 analysis software (BioRad). As required for statistical analysis, four biological replications of each group, artificial inoculation and control were used to create 'replicate groups' for each grain development stage. Spot detection and matching were carried out by using the automated 'spot detection wizard'. Spots that were present in at least three of the group members were added to the analysis set. The spot quantities in four control samples were compared with the spot quantities in four inoculated samples. For statistical analysis sets, the student's $t$-test with significance level of $90 \%$ was chosen. The standard deviation between four replicate groups was under $50 \%$. Protein spots were accepted to change after F. graminearum infection if the difference between the mean values of control and artificially inoculated samples was higher than the factor of two or if a protein spot exclusively appeared in one group.

\section{Protein identification by mass spectrometry}

Tryptic digestion of proteins and identification of proteins by mass spectrometry (MS) were performed as described by Klodmann et al. (22). Procedures were based on peptide separation using the EASY-nLC System (Proxeon; Thermo Scientific, Bremen, Germany) and coupled 
MS analyses using the MicrOTOF-Q II mass spectrometer (Bruker, Bremen, Germany). MS data evaluation was carried out using ProteinScape v. 2.1 software (Bruker) and the Mascot search algorithm (Matrix Science, London, UK) against: (i) the NCBI protein database (23), (ii) the UniProt protein database (24) and (iii) the Arabidopsis protein database (25). The following Mascot search parameters were used: enzyme: trypsin/ $\mathrm{P}$ (up to one missed cleavage allowed); global modification: carbamidomethylation $(\mathrm{C})$, variable modifications: acetyl $(\mathrm{N})$, oxidation (M); precursor ion mass tolerance: $15 \mathrm{ppm}$; fragment ion mass tolerance: $0.6 \mathrm{Da}$; peptide charge: $1+, 2+$, and $3+$; instrument type: electrospray ionization quadrupole time of flight. Minimum ion score was 30, minimum peptide length was four amino acids, significance threshold was set to 0.05 and protein and peptide assessments were carried out if the Mascot score was greater than 30 for proteins and 20 for peptides.

\section{Results and Discussion}

In this study we inoculated emmer grains with a spore suspension of Fusarium graminearum at anthesis. The regulation of specific proteins due to Fusarium inoculation compared to a non-inoculated control was investigated in four ripening stages of the grains by proteomic analysis.

\section{Fusarium DNA and DON content}

Table 2 shows the content of F. graminearum DNA and DON at different ripening stages of emmer grains. In the samples, the F. graminearum DNA content was below the limit of quantification (LOQ). After artificial inoculation, $4.1 \mathrm{mg}$ of $F$. graminearum DNA per $\mathrm{kg}$ of dry matter was detected already at BBCH 75. The DNA amount increased up to $21.3 \mathrm{mg} / \mathrm{kg}$ at $\mathrm{BBCH}$ 97. DON contents were significantly increased in emmer grains after artificial inoculation (Table 2). Control grains showed no detectable DON. The significantly higher amount of F. graminearum DNA and DON content in inoculated plants as compared to control plants showed that the inoculation was successful.

\section{Proteome analysis}

After artificial F. graminearum infection a total of 52 proteins showed different expression patterns regarding all development stages (Fig. 1). At BBCH 75 and 85 the abundance of eight proteins increased due to Fusarium in- fection, whereas at $\mathrm{BBCH} 87$, that of six proteins and at $\mathrm{BBCH} 97$ only of three proteins increased (Fig. 1). On the contrary, no proteins were detected to be reduced at $\mathrm{BBCH} 75$, whereas six proteins showed reduced expression at $\mathrm{BBCH} 85$. The abundance of nine proteins decreased at $\mathrm{BBCH} 87$ as well as of 12 proteins at $\mathrm{BBCH} 97$ (Fig. 1). In summary, during earlier development stages, protein expression rather increased due to artificial F. graminearum infection, whereas proteins were predominantly reduced at later grain ripening stages. Proteins could be identified by LC-MS according to their peptide sequences after trypsin digestion and database search.

\section{Oxidative burst-related proteins}

In all development stages the abundance of proteins related to oxidative stress changed due to Fusarium infection. Table 3 shows changes of enzymes related to oxidative stress after Fusarium inoculation. Altogether, three antioxidative proteins were identified: a peroxidase, 2-Cys peroxiredoxin and a manganese superoxide dismutase. In the early grain development at $\mathrm{BBCH} 75$, peroxidase 1 increased by a factor of 2.9 , and by a factor of 6.3 at $\mathrm{BBCH} 87$ in the inoculated grains compared to the control grains, whereupon the protein was exclusively expressed in the inoculated grains at $\mathrm{BBCH} 97$. The 2-Cys peroxiredoxin increased in the early grain development at $\mathrm{BBCH} 75$ and 85 and decreased at $\mathrm{BBCH} 87$ and 97. Furthermore, the abundance of a manganese superoxide dismutase was found to decrease at BBCH 85.

The increased accumulation of antioxidant enzymes in the grains suggests an oxidative burst after the infection with F. graminearum. Plants produce high levels of reactive oxygen species (ROS) such as hydrogen peroxide as a response to biotic or abiotic stress (26). Part of defence against biotrophic pathogens, oxidative burst contributes to the hypersensitive response and consequently to cell death at the site of the pathogen infection, limiting the pathogen spread to adjacent tissues. On the other hand, the plants produce antioxidants and ROS-scavenging enzymes to detoxify these reactive molecules (27). ROS are also involved in cellular signalling pathways associated with the induction of defence responses. Their regulation by antioxidative enzymes is proposed to play an important role in plant defence, since the ROS levels during oxidative burst mediate complex cell signalling networks $(26,28)$. Peroxidases are furthermore involved in lignin-polysaccharide cross linking in plant cell walls, leading to higher resistance of the cell wall against enzy-

Table 2. Fusarium DNA content of emmer grain infolding tissues (glumes and rachis) and deoxynivalenol (DON) content of grains during ripening

\begin{tabular}{|c|c|c|c|c|}
\hline \multirow{3}{*}{$\mathrm{BBCH}$} & \multicolumn{2}{|c|}{ Control } & \multicolumn{2}{|c|}{ Inoculation } \\
\hline & $w($ Fusarium DNA) & $w(\mathrm{DON})$ & $w$ (Fusarium DNA) & $w(\mathrm{DON})$ \\
\hline & $\mathrm{mg} / \mathrm{kg}$ & $\mathrm{mg} / \mathrm{kg}$ & $\mathrm{mg} / \mathrm{kg}$ & $\mathrm{mg} / \mathrm{kg}$ \\
\hline 75 & $<\mathrm{LOQ}$ & $<\mathrm{LOD}$ & $4.1 \pm 1.6$ & $15.0 \pm 7.3$ \\
\hline 85 & $<\mathrm{LOQ}$ & $<\mathrm{LOD}$ & $7.4 \pm 3.4$ & $18.6 \pm 5.6$ \\
\hline 87 & $<\mathrm{LOQ}$ & $<\mathrm{LOD}$ & $7.6 \pm 3.8$ & $14.9 \pm 3.2$ \\
\hline 97 & $<\mathrm{LOQ}$ & $<\mathrm{LOD}$ & $21.3 \pm 9.7$ & $15.9 \pm 2.8$ \\
\hline
\end{tabular}

The values are expressed as mean \pm standard deviation. $\mathrm{BBCH}=$ see Table $1, \mathrm{LOQ}=\mathrm{limit}$ of quantification $(0.02 \mathrm{mg} / \mathrm{kg}), \mathrm{LOD}=\mathrm{limit}$ of detection 


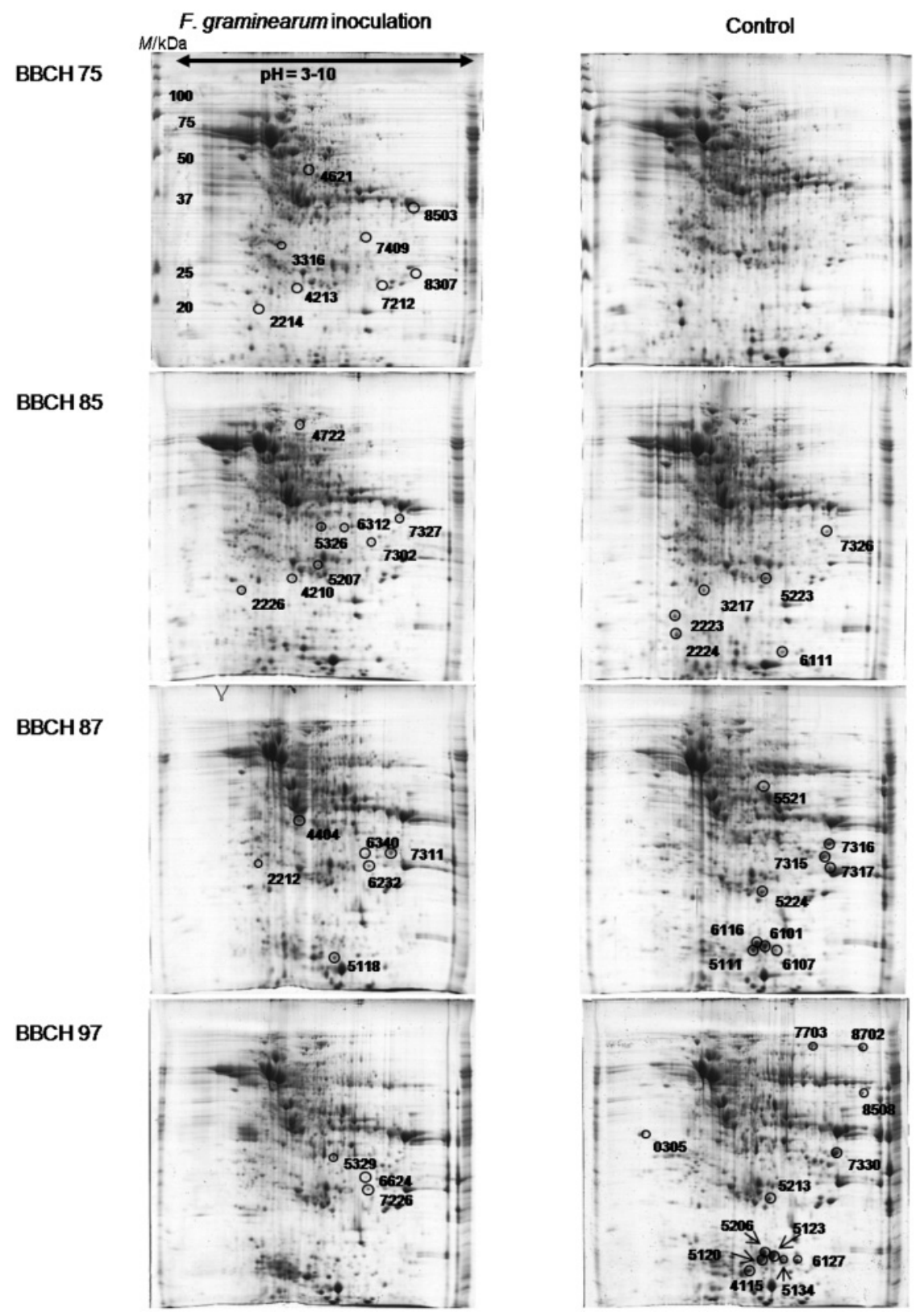

Fig. 1. Two-dimensional protein gels of emmer grains (12 \% SDS-PAGE, immobilized pH gradient: $\mathrm{pH}=3-10,17 \mathrm{~cm}$ linear strip, Coomassie G250-stained) at four development stages (BBCH 75, 85, 87 and 97, see Table 1) inoculated with F. graminearum and from control plots (see Materials and Methods). Spots of changed volume are encircled and numbered with IDs. BBCH=Biologische Bundesanstalt, Bundessortenamt und Chemische Industrie (Federal Institute of Biology, Federal Plant Variety Office and Chemical Industry), Germany

Table 3. Changes in the abundance of proteins related to oxidative burst due to artificial $F$. graminearum inoculation compared to control during grain ripening stages of emmer

\begin{tabular}{lcccc}
\hline \multirow{2}{*}{ Protein } & \multicolumn{4}{c}{ BBCH stage } \\
\cline { 2 - 5 } & 75 & 85 & 87 & 97 \\
\hline Peroxidase 1 & +2.9 & & +6.3 & $+\infty$ \\
2-Cys peroxiredoxin BAS1 & $+\infty$ & +3.1 & -3.7 & -10.8 \\
$\begin{array}{l}\text { Manganese superoxide } \\
\text { dismutase }\end{array}$ & -4.2 & & \\
\hline
\end{tabular}

BBCH=see Table $1,+=$ increased abundance, $-=$ decreased abundance, $+\infty=$ protein found only in artificially inoculated grains matic hydrolysis (29). In addition, ROS have been identified to induce DON biosynthesis in F. graminearum, whereas the presence of catalase reduced DON accumulation (30).

\section{Pathogenesis-related proteins}

An important plant strategy to inhibit fungal growth is the induction of PR proteins. These proteins are known to be induced in plants that are exposed to pathogens. They are assumed to protect plants against pathogenic microorganisms and various pests as well as abiotic stress (31). In the present study the abundance of PR protein levels in emmer grains changed after Fusarium infection (Table 4). 
Table 4. Changes in the abundance of pathogenesis-related proteins due to artificial F. graminearum inoculation compared to control during grain ripening stages of emmer

\begin{tabular}{llcc}
\hline \multirow{2}{*}{ Protein } & Function & \multicolumn{2}{c}{ BBCH stage } \\
\cline { 3 - 4 } Class II chitinase & Chitin catabolic process & 75 & 87 \\
Basic endochitinase A (class I) & Chitin catabolic process & +2.5 & -10.5 \\
Predicted (chitin-binding) protein & Chitin binding & -12.5 & -11.5 \\
Xylanase inhibitor XIP-III & Inhibition of fungal spread & +3.6 & $+\infty$ \\
Predicted (small heat shock) protein & Protein folding & +2.6 & $-\infty$ \\
HSP 70 (heat shock protein) & Protein folding & $-\infty$ \\
Hypothetical protein & Defence response & -3.5 & -8.1 \\
Globulin & $\alpha$-amylase inhibitor & & \\
\hline
\end{tabular}

$\mathrm{BBCH}=$ see Table $1,+=$ increased abundance, $-=$ decreased abundance, $+\infty=$ protein found only in artificially inoculated grains; $-\infty=$ protein found only in control grains

Several of these proteins belong to the group of chitinases. Chitinases catalyse the hydrolysis of chitin, a linear polymer of $\beta$-1,4-linked $N$-acetyl glucosamine. The amino acid sequences of chitinase subfamilies I and II are highly similar. The main difference is that class I chitinases possess a cysteine-rich chitin-binding domain, which has no catalytic function but is suggested to promote the catabolic activity of the enzymes (32). Besides pathogen infection, chitinase production depends on various biotic and abiotic stress factors, such as wounding, heavy metals, drought and cold stress. The enzymes protect plants directly by destroying fungal cell walls and indirectly by generating oligomers of chitin which act as signal molecules, including further defence responses $(32,33)$. In the present study, the amount of chitinases predominantly decreased. Nevertheless, the amount of a class II endochitinase increased after Fusarium infection in the early grain development at $\mathrm{BBCH} 75$ and later decreased at $\mathrm{BBCH}$ 87. Furthermore, the amount of a class I endochitinase decreased at $\mathrm{BBCH}$ 87 and 97. Interestingly, in the later stages of infection at $\mathrm{BBCH} 87$ and 97 the amount of a 'predicted protein' containing a chitin-binding domain increased. Similarly, chitinase in the spikelets of barley was increased with $F$. graminearum infection three days after inoculation (12). Proteome analysis of mature emmer grains after Fusarium infection showed that the amount of class II chitinase was reduced. The authors suggested that a fungal signal was responsible for the effect (14). Lutz et al. (34) discovered that DON-producing F. culmorum and F. graminearum strains inhibit the expression of a chitinase gene from Trichoderma atroviride, demonstrating a possible fungal control of gene regulation concerning chitinase expression.

A xylanase inhibitor protein (XIP), playing a role in plant defence against fungi, increased at $\mathrm{BBCH} 85$ with a factor of 2.6. These proteins belong to the glycosyl hydrolase 18 family, similar to chitinases. These proteins inhibit cell wall-degrading fungal xylanases and therefore inhibit pathogen spread. According to Dornez et al. (13), the abundance of some isoforms of xylanase inhibitor increased, whereas of others decreased since 5 days post anthesis. During grain ripening the abundance of most xylanase inhibitors increased.

Two heat shock proteins (HSP) decreased at $\mathrm{BBCH}$ 87. HSPs are known to assist in the correct folding of polypeptides as molecular chaperones and assist the re- folding of non-native proteins. They are known to play a role in protecting plants from stress by securing correct protein conformation under stress conditions (35).

An $\alpha$-amylase inhibitor decreased by a factor of 8.1 at $\mathrm{BBCH}$ 87. Alpha-amylase inhibitors protect the starch of the endosperm from fungal degradation. The abundance of most of the PR proteins decreased especially in the later stage of grain development starting with $\mathrm{BBCH}$ 87. It remains unclear whether the pathogen inhibited the formation of PR proteins or the abundance of PR proteins was reduced as a side-effect of the redirection of plant resources to other defence mechanisms such as cell-wall thickening and phytoalexin accumulation.

\section{Energy metabolism, carbohydrate metabolism and photosynthesis-related proteins}

A number of various proteins changed after F. graminearum infection are involved in energy and carbohydrate metabolisms, photosynthesis and starch and protein synthesis. Especially in the earlier ripening stages, the content of proteins involved in glycolysis, citric acid cycle and electron transport chain increased (Table 5). Zhou et al. (9) suggested a possible connection of glycolysis between F. graminearum and wheat to benefit the carbon assimilation of the fungus.

The amount of another protein, spermidine synthase, increased by a factor of 4.2 at $\mathrm{BBCH} 75$. Spermidine synthase is involved in the biosynthesis of the polyamine spermidine. Polyamines occur in all living cells. They are involved in several cellular processes such as gene expression, translation, cell division and development as well as cell signalling (36). Polyamines are also involved in stress response and resistance to pathogen infection (37). It has been determined that some intermediates and products of the polyamine pathway, such as agmatine and putrescine, are strong inducers of TRI5 gene expression in vitro and therefore inducers of DON production (38). DON is known to be a virulence factor promoting fungal spread within wheat spikelets (39). Gardiner et al. (40) observed a significant increase in putrescine and spermidine in $F$. graminearum-infected wheat heads one to seven days after inoculation in comparison with a mock inoculation.

Furthermore, polyamines (putrescine, spermine and spermidine) are amongst other functions suggested to be 
Table 5. Changes in the abundance of proteins related to energy and carbon metabolism and photosynthesis due to artificial $F$. graminearum inoculation compared to control during grain ripening stages of emmer

\begin{tabular}{|c|c|c|c|c|c|}
\hline \multirow{2}{*}{ Protein } & \multirow{2}{*}{ Function } & \multicolumn{4}{|c|}{$\mathrm{BBCH}$ stage } \\
\hline & & 75 & 85 & 87 & 97 \\
\hline Glucose and ribitol dehydrogenase homologue & Carbohydrate metabolism & +2.8 & +9.9 & & +5.9 \\
\hline Glyceraldehyde-3-phosphate dehydrogenase & Glycolysis & +3.4 & & & \\
\hline Succinate dehydrogenase & Citric acid cycle, electron transport chain & & & +10.1 & \\
\hline Glucose-1-phosphate adenylyltransferase & Glycan/starch biosynthesis & +3 & & & \\
\hline Pyruvate, phosphate dikinase 1 (proteolytic fragment) & Photosynthesis & +5.4 & & & \\
\hline Ferredoxin-NADP reductase & Photosynthesis, energy metabolism & & +6.6 & & \\
\hline Eukaryotic translation initiation factor 6-2 & Protein biosynthesis & & & $+2,5$ & \\
\hline $60 S$ acidic ribosomal protein $\mathrm{P} 0$ & Protein biosynthesis & & & +4.9 & \\
\hline Spermidine synthase & & +4.2 & & & \\
\hline
\end{tabular}

BBCH=see Table 1, +=increased abundance, $-=$ decreased abundance

involved in ROS-scavenging processes (41). In a study by Jang et al. (42) an increased polyamine biosynthesis prevented the accumulation of reactive oxygen species in rice. Additionally, an enhanced expression of ROS-detoxifying enzymes was found, associated with higher polyamine content.

At $\mathrm{BBCH} 85,87$ and 97 stages, the abundance of several predicted proteins with currently unknown functions decreased. Furthermore, some of the identified and unidentified proteins were apparently proteolytic fragments.

\section{Conclusions}

To our knowledge this is the first proteomic study analysing the effect of $F$. graminearum infection on cereal grains covering all ripening stages from early grain development until plant death. We found that inoculation of emmer with F. graminearum led to changes of protein expression in all development stages. In the early ripening stages, proteins predominantly related to metabolism and photosynthesis as well as stress-related proteins such as PR proteins and proteins related to oxidative stress were up-regulated. Additionally, a spermidine synthase was up-regulated at $\mathrm{BBCH} 75$. During later ripening stages, at $\mathrm{BBCH} 87$ and 97, the abundance of stress-related proteins decreased. Nevertheless, the abundance of some stress-related proteins, such as peroxidase and chitin-binding proteins, increased in after $F$. graminearum infection during later grain ripening stages, demonstrating that some defence strategies were persistent during the whole infection period. It is imaginable that the pathogen benefits from the enhanced metabolism, since plant metabolites serve as nutrients for fungal growth. The results identify molecular mechanisms initiated by F. graminearum infection of emmer grains. Further studies may compare susceptible and resistant emmer and wheat cultivars concerning their response to pathogen attack at different grain ripening stages to understand the response mechanisms of cereals during the entire infection period.

\section{Acknowledgements}

This work is part of the FAEN Joint Project 3 'Quality related plant production under modified basic condi- tions: mycotoxins in the context of production, quality and processing', financed by the Ministry of Science and Culture of Lower Saxony, Germany.

\section{References}

1. Bottalico A, Perrone G. Toxigenic Fusarium species and mycotoxins associated with head blight in small-grain cereals in Europe. Eur J Plant Pathol. 2002;108:611-24. http://dx.doi.org/10.1023/A:1020635214971

2. Kazan K, Gardiner DM, Manners JM. On the trail of a cereal killer: recent advances in Fusarium graminearum pathogenomics and host resistance. Mol Plant Pathol. 2012;13:399-413. http://dx.doi.org/10.1111/J.1364-3703.2011.00762.X

3. Champeil A, Doré T, Fourbet J. Fusarium head blight: epidemiological origin of the effects of cultural practices on head blight attacks and the production of mycotoxins by Fusarium in wheat grains. Plant Sci. 2004;166:1389-415. http://dx.doi.org/10.1016/j.plantsci.2004.02.004

4. Ruckenbauer P, Buertmayr H, Lemmens M. Present strategies in resistance breeding against scab (Fusarium spp.). Euphytica. 2001;119:121-7.

5. Zaharieva M, Ayana NG, Hakimi AA, Misra SC, Monneveux P. Cultivated emmer wheat (Triticum dicoccon Schrank), an old crop with promising future: a review. Genet Resour Crop Evol. 2010;57:937-62. http://dx.doi.org/10.1007/s10722-010-9572-6

6. Buerstmayr $\mathrm{H}$, Stierschneider M, Barbara S, Lemmens $M$, Griesser M, Eviatar N, Fahima T. Variation for resistance to head blight caused by Fusarium graminearum in wild emmer (Triticum dicoccoides) originating from Israel. Euphytica. 2003;130:17-23.

7. Oliver RE, Stack RW, Miller JD, Cai X. Reaction of wild emmer wheat accessions to Fusarium head blight. Crop Sci. 2007;47:893-9. http://dx.doi.org/10.2135/cropsci2006.08.0531

8. Wang Y, Yang L, Xu H, Li Q, Ma Z, Chu C. Differential proteomic analysis of proteins in wheat spikes induced by Fusarium graminearum. Proteomics. 2005;5:4496-503. http://dx.doi.org/10.1002/pmic.200401317

9. Zhou W, Eudes F, Laroche A. Identification of differentially regulated proteins in response to a compatible interaction between the pathogen Fusarium graminearum and its host, Triticum aestivum. Proteomics. 2006;6:4599-609. http://dx.doi.org/10.1002/pmic.200600052 
10. Shin KH, Kamal AHM, Cho K, Choi JS, Jin Y, Paek NC, et al. Defense proteins are induced in wheat spikes exposed to Fusarium graminearum. POJ. 2011;4:270-7.

11. Yang F, Jensen JD, Svensson B, Jørgensen HJ, Collinge DB, Finnie C. Analysis of early events in the interaction between Fusarium graminearum and the susceptible barley (Hordeum vulgare) cultivar Scarlett. Proteomics. 2010;10:3748-55. http://dx.doi.org/10.1002/pmic.201000243

12. Geddes J, Eudes F, Laroche A, Selinger LB. Differential expression of proteins in response to the interaction between the pathogen Fusarium graminearum and its host, Hordeum vulgare. Proteomics. 2008;8:545-54.

http://dx.doi.org/10.1002/pmic.200700115

13. Dornez E, Croes E, Gebruers K, Carpentier S, Swennen R, Laukens $K$, et al. 2-D DIGE reveals changes in wheat xylanase inhibitor protein families due to Fusarium graminearum $\Delta$ Tri5 infection and grain development. Proteomics. 2010;10:2303-19. http://dx.doi.org/10.1002/pmic.200900493

14. Eggert K, Zörb C, Mühling KH, Pawelzik E. Proteome analysis of Fusarium infection in emmer grains (Triticum dicoccum). Plant Pathol. 2011;60:918-28.

http://dx.doi.org/10.1111/j.1365-3059.2011.02442.x

15. Eggert K, Pawelzik E. Proteome analysis of Fusarium head blight in grains of naked barley (Hordeum vulgare subsp. nudum). Proteomics. 2011;11:972-85. http://dx.doi.org/10.1002/pmic.201000322

16. Gao L, Wang A, Li X, Dong K, Wang K, Appels R, et al. Wheat quality related differential expressions of albumins and globulins revealed by two-dimensional difference gel electrophoresis (2-D DIGE). J Prot. 2009;73:279-96.

http://dx.doi.org/10.1016/j.jprot.2009.09.014

17. Meier U. Growth stages of mono- and dicotyledonous plants. 2001. Available from: http://pub.jki.bund.de/index. $\mathrm{php} / \mathrm{BBCH}$

18. Brandfass C, Karlovsky P. Simultaneous detection of Fusarium culmorum and F. graminearum in plant material by duplex PCR with melting curve analysis. BMC Microbiol. 2006;6:4. http://dx.doi.org/10.1186/1471-2180-6-4

19. Brandfass C, Karlovsky P. Upscaled CTAB-based DNA extraction and real-time PCR assays for Fusarium culmorum and F. graminearum DNA in plant material with reduced sampling error. IJMS. 2008;9:2306-21. http://dx.doi.org/10.3390/ijms9112306

20. Adejumo T, Hettwer U, Karlovsky P. Occurrence of Fusarium species and trichothecenes in Nigerian maize. Int J Food Microbiol. 2007;116:350-7.

21. Candiano G, Bruschi M, Musante L, Santucci L, Ghiggeri GM, Carnemolla B, et al. Blue silver: a very sensitive colloidal Coomassie G-250 staining for proteome analysis. Electrophoresis. 2004; 25:1327-33. http://dx.doi.org/10.1002/elps.200305844

22. Klodmann J, Sunderhaus S, Nimtz M, Jansch L, Braun HP. Internal architecture of mitochondrial complex I from Arabidopsis thaliana. Plant Cell. 2010;22:797-810. http://dx.doi.org/10.1105/tpc.109.073726

23. Protein Database, Bethesda, MD, USA: National Center for Biotechnology Information (NCBI). http://www.ncbi.nih.org

24. Universal Protein Resource (UniProt), UniProt Consortium. http://www.uniprot.org

25. The Arabidopsis Information Resource (TAIR), Release 10. Redmond City, CA, USA; Phoenix Bionformatics. http:// www.Arabidopsis.org

26. Torres MA. ROS in biotic interactions. Physiol Plantarum. 2010;138:414-29.

http://dx.doi.org/10.1111/j.1399-3054.2009.01326.x

27. Atkinson NJ, Urwin PE. The interaction of plant biotic and abiotic stresses: from genes to the field. J Exp Bot. 2012;63: 3523-43. http://dx.doi.org/10.1093/jxb/ers100

28. O'Brien JA, Daudi A, Butt VS, Bolwell GP. Reactive oxygen species and their role in plant defence and cell wall metabolism. Planta. 2012;236:765-79.

http://dx.doi.org/10.1007/s00425-012-1696-9

29. Ralph J, Bunzel M, Marita JM, Hatfield RD, Lu F, Kim H, et al. Peroxidase-dependent cross-linking reactions of p-hydroxycinnamates in plant cell walls. Phytochem Rev. 2004;3:79-96.

30. Ponts N, Pinson-Gadais L, Barreau C, Richard-Forget F, Ouellet T. Exogenous $\mathrm{H}_{2} \mathrm{O}_{2}$ and catalase treatments interfere with Tri genes expression in liquid cultures of Fusarium graminearum. FEBS Lett. 2007;581:443-7. http://dx.doi.org/10.1016/j.febslet.2007.01.003

31. van Loon $\mathrm{L}$, van Strien E. The families of pathogenesis-related proteins, their activities, and comparative analysis of PR-1 type proteins. Physiol Mol Plant Pathol. 1999;55:85-97.

32. Ubhayasekera W. Structure and function of chitinases from glycoside hydrolase family 19. Polym Int. 2011;60:890-6. http://dx.doi.org/10.1002/pi.3028

33. Sarma K, Dehury B, Sahu J, Sarmah R, Sahoo S, Sahu M, et al. A comparative proteomic approach to analyse structure, function and evolution of rice chitinases: a step towards increasing plant fungal resistance. J Mol Model. 2012;18:4761-80. http://dx.doi.org/10.1007/s00894-012-1470-8

34. Lutz MP, Feichtinger G, Defago G, Duffy B. Mycotoxigenic Fusarium and deoxynivalenol production repress chitinase gene expression in the biocontrol agent Trichoderma atroviride P1. Appl Environm Microbiol. 2003;69:3077-84.

35. Wang W, Vinocur B, Shoseyov O, Altman A. Role of plant heat-shock proteins and molecular chaperones in the abiotic stress response. Trends Plant Sci. 2004;9:244-52. http://dx.doi.org/10.1016/j.tplants.2004.03.006

36. Kusano T, Berberich T, Tateda C, Takahashi Y. Polyamines: essential factors for growth and survival. Planta. 2008;228: 367-81. http://dx.doi.org/10.1007/s00425-008-0772-7

37. Walters D. Resistance to plant pathogens: possible roles for free polyamines and polyamine catabolism. New Phytol. 2003;159:109-15. http://dx.doi.org/10.1046/j.1469-8137.2003.00802.x

38. Gardiner DM, Kazan K, Manners JM. Nutrient profiling reveals potent inducers of trichothecene biosynthesis in Fusarium graminearum. Fungal Genet Biol. 2009;46:604-13. http://dx.doi.org/10.1016/j.fgb.2009.04.004

39. Jansen C, von Wettstein D, Schäfer W, Kogel KH, Felk A, Maier FJ. Infection patterns in barley and wheat spikes inoculated with wild-type and trichodiene synthase gene disrupted Fusarium graminearum, PNAS. 2005;102:16892-7. http://dx.doi.org/10.1073/pnas.0508467102

40. Gardiner DM, Kazan K, Praud S, Torney FJ, Rusu A, Manners JM. Early activation of wheat polyamine biosynthesis during Fusarium head blight implicates putrescine as an inducer of trichothecene mycotoxin production. BMC Plant Biol. 2010;10:289.

http://dx.doi.org/10.1186/1471-2229-10-289

41. Rhee HJ, Kim E, Lee JK. Physiological polyamines: simple primordial stress molecules. J Cel Mol Med. 2007;11:685-703. http://dx.doi.org/10.1111/j.1582-4934.2007.00077.x

42. Jang SJ, Wi SJ, Choi YJ, An G, Park KY. Increased polyamine biosynthesis enhances stress tolerance by preventing the accumulation of reactive oxygen species: T-DNA mutational analysis of Oryza sativa lysine decarboxylase-like protein 1 . Mol Cells. 2012;34:251-62.

http://dx.doi.org/10.1007/s10059-012-0067-5 